\title{
Crowdfunding Platforms and the Design of Paying Publics
}

\author{
Ann Light \\ School of Engineering and Informatics \\ University of Sussex, Falmer, UK \\ Ann.Light@sussex.ac.uk
}

\begin{abstract}
Crowdfunding enables groups to self-fund the changes they want to make in the world. In other words, digital financial platforms are proving capable of supporting new relations between groups of people as well as offering new ways to organize money. Taking an HCI lens, we look at how some crowdfunding platform owners are approaching social innovation, not only at the level of supporting individual community initiatives, but at the broader level of using their platform to change societal behavior. Through four case studies, we show how crowdfunding has been chosen as a tool to redesign society by promoting environmental or social sustainability. We argue that the groups constituted through these interactions are not merely 'crowds', but deliberate constellations built round a thing of interest (or 'paying publics'). Our interviews with managers and owners explore how interactions with and around platforms work to achieve these ends and we conclude with design considerations.
\end{abstract}

\section{Keywords}

Digital platforms; sustainability; platform design; social innovation; paying publics; business models; infrastructure.

\section{ACM Classification Keywords}

H.5.m. Information interfaces and presentation (e.g., HCI): Miscellaneous.

\section{INTRODUCTION}

New peer-to-peer (P2P) platforms offer new arrangements for financing, using new digital aggregation and network tools. The range stretches from quasi-banks (e.g Zopa.com), to campaign fundraising for enterprises or causes (e.g. Kickstarter.com) to charitable giving (e.g. JustGiving.com). Inevitably, connecting up people and money in new ways leads to changes of practice. However, little attention has been paid to crowdfunding innovators hoping to change, not just individual aspects of a community or business fundraising campaign, but how the world works. Noting

Permission to make digital or hard copies of part or all of this work for personal or classroom use is granted without fee provided that copies are not made or distributed for profit or commercial advantage and that copies bear this notice and the full citation on the first page. Copyrights for thirdparty components of this work must be honored. For all other uses, contact the Owner/Author.

Copyright is held by the owner/author(s).

CHI 2017, May 06-11, 2017, Denver, CO, USA

ACM 978-1-4503-4655-9/17/05.

http://dx.doi.org/10.1145/3025453.3025979.

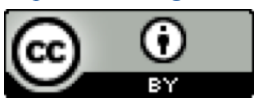

This work is licensed under a Creative Commons Attribution International 4.0 License.

\author{
Jo Briggs \\ School of Design \\ University of Northumbria at Newcastle \\ Jo.Briggs@northumbria.ac.uk
}

that money sits at the heart of much of society and its interactions, we use this paper to present the ambitions of four UK crowdfunding platforms with social change goals. (For reasons of space and focus, we are neither attempting to validate their achievements here, nor take the views of campaign organizers and funders into account.) We wish to bring before $\mathrm{CHI}$ a look at the potential crowdfunding offers to change societal relations at a fundamental level and make social as well as financial innovation.

Our contribution is to reveal how platform owners are experimenting to restructure people's socio-economic relations through payments and to ask in which ways platforms might be seen to configure publics. In doing this, we show the link these producers are making between financial models and the nature of future society. And we challenge the use of the term 'crowd' to capture the subtlety of the relationships that platform design can support, arguing instead for a class of DIY 'paying publics'.

To achieve this, we share excerpts from interviews with platform owners and their teams in which they articulate their ambitions over several years, and how they hope to achieve them. We present four case studies - two with an environmental sustainability angle and two focusing on social sustainability. We are not asking readers to judge the success of the platforms, one of which has already closed to new business, but to consider with us what the implications of bringing people together around a collective issue may be and how this might be regarded as both a new path to funding and a significant evolution in societal relations. We are using examples from the UK, which is world-leading in its variety of crowdfunding initiatives [40].

We begin with an overview of where crowdfunding sits as a money management system. We draw on social science and recent HCI work on the formation of crowds and publics (c.f. $[14,29]$ ) to establish a position on the constellations of people and groups within which crowdfunding platforms operate. We then present four crowdfunding platforms, picked because of their owners' intentions to make social change. We close with analysis of the connection between these societal ambitions and design choices, exploring the idea of paying publics as a series of design considerations.

\section{BACKGROUND}

Crowdfunding brings distinct but interdependent markets together to co-create value in new ways [43]. Especially for social innovation undertakings, it offers a welcome new approach at a time of shrinking state support. 
The innovation hinges on the potential of digital platforms. Gawer [18] defines a digital platform as 'a building block, providing an essential function to a technological system which acts as a foundation upon which other firms can develop complementary products, technologies or services' (p2). In other words, a platform is infrastructure, something to be built on, and its design will influence, but not determine, what can be built on it [6]. Working alongside the design features of the platform are the social, economic and legal aspects of financial systems that evolve over time and also constrain what platforms can enable.

Is the co-shaping of social and financial structures new? Society has long had mechanisms for both redistributing wealth and payment for services and other societal goods. These vary from intensely local, (neighborhood lending circles and subscription activities for clubs) to global, (the banking system), including the establishment of local authorities to manage resource distribution. Each culture has shaped and been shaped by how transaction is managed (e.g. $[5,36])$. In the UK, where this study took place, banks, and mutual initiatives, such as credit unions and building societies, provide management for finances. Taxation by the state and municipality pays for collective services and redistributes some wealth. These tools of collaborative living evolved over centuries, responding to political conditions. Crowdfunding is one of a long line of devices for managing the movement and exchange of value, now part of the "collaborative economy" (e.g. timebanking $[3,7,8]$, sharing services $[31,32])$, in which networks change potential. Particularly when we look at crowdfunding for social innovation, we see a new socio-economic mechanism with a long history of collective funding activity behind it.

So, what is new? The Web brings connections between 'the many and the many' [42:111], allowing scaling of systems globally through distributed participants. Digital micropayments on an industrial scale are possible, meaning new interactions can be monetized and individual small returns can be amassed. Platforms are low cost to run, needing comparatively little support. They can act as brokers or trading partners using algorithms that handle matchmaking, data aggregation and other decisions. They evolve fast in response to new technical opportunities, usage patterns and legal and regulatory issues.

At the same time, driving innovation in the arts, state and voluntary sectors in Britain, and elsewhere, is the loss of much public funding and the prospect of more cuts. A neoliberal agenda is promoting market mechanisms at the expense of interventionist and more collectivist approaches and new network paradigms may feed into this trend [21]. Though individual countries have different stories based on their economic orientations, there is an overall shift toward self-help at community level and away from government support. Despite old policies of state provision, there is, more recently, growing inequality in income and wealth accompanying a shrinking tax base as the population ages.
UK municipalities are struggling to be the providers they became in the $20^{\text {th }}$ century, taking instead enabling roles like place-shaping [34].

Crowdfunding has drawn considerable recent research [e.g $1,2,12,13,19,23,37,38,39,41,50,54,55]$ along with design for crowds [49]. Of relevance to this paper is the growing field of civic crowdfunding $[13,50]$ where crowdfunding acts as service design for mobilizing social innovation, generating value through 'community or quasi-public assets' ([13: 342]). Early on, Murray et al [42] observed potential for collective funding that was still nascent in 2009: 'A group with a shared interest may want to act collectively as consumers, or workers, or investors in a project. ... But in that they are acting collectively, they are part of the social economy in a way that is distinct both from the private economy, and from charities. ...For all those investing, it is a particular form of collective financing and ownership' (p113). More recently, some literature sets up a contrast between philanthropic motivations and those focused on capital-raising. Agrawal et al [1] describe funder motivation as quite binary: giving for the common good or for a good return. However, others (e.g. [50]) detail a more symbiotic relationship, with a measure of self-interest apparent among those who donate to local social projects. Investing money as crowdfunding can reinforce commitment to an activity, being qualitatively different from voting to give go-ahead [41] and more like participatory budgeting [44]. And success with platforms draws repeat borrowers away from banks and towards P2P lending [47].

\section{Types of Crowdfunding}

The UK is a major center for crowdfunding expertise and activities [40], supported by light-touch regulation and government investment. Part of the reason for the UK's leadership is that, till May 2016 and implementation of the JOBS Act (with a subsection on crowdfunding) [24], equity crowdfunding was not legal in the US, so major innovation as well as less commercial projects had to take a rewards route, on platforms such as Kickstarter [27].

UK platforms come in many shapes that we can expect to see propagate. Research [2] and practice (e.g. database for UK founders [11]) has adopted a four-part classification:

- Donation-based: philanthropically and socio-politically motivated and no tangible goods are exchanged.

- Rewards-based: fundraisers solicit money within a timelimit in return for a tangible reward: All Or Nothing: fundraisers must reach a pre-agreed funding goal to claim pledged money; Keep It All: they take any money raised.

- Equity: funders enter formal agreements with business start-ups or other enterprises in exchange for equity and with a view to realizing a profit over time.

- Loan-based or P2P: platforms broker deals; funders lend to fundraisers for a pre-agreed period and interest rate.

Design research has largely followed US commercial and legal contingencies, so much existing work focuses on reward-based campaigns, their motivations [e.g. 19] and 
how to make them effective [e.g.12,23,37,38,54,55]. The Kickstarter platform has garnered most HCI research (e.g. $[2,19,38])$, not least because its campaigns remain public even after closure, providing a ready corpus of data, at scale. More challenging is acquiring access to $\mathrm{P} 2 \mathrm{P}$ and equity platforms' data, such as these here, as these platforms often keep campaigns private. But these data point the way to concerns that are now going worldwide.

Of particular relevance here is research showing the impact of campaign organizers' use of platform messaging tools at campaign milestones in facilitating a completed campaign [54], the effect of language in soliciting additional pledges [37], ideas of community among fundraisers and supporters, and how creatives support each other through the social functions of online tools [23]. These suggest the importance of the interface, but also of the design of the process that platforms offer campaign organizers to engage, update, keep on board and build up their sponsors.

\section{CROWDS VS PUBLICS}

In addressing crowdfunding, we cannot miss the word crowd. We suggest that, in looking at activity with and round platforms, we are not served well by this term. Instead, we argue that participants in a crowdfunding ecosystem for social innovation meet the definition of public (cf $[14,29]$ ), with common interests growing through an investment of time and/or resources in related outcomes.

\section{Constellations}

Platforms link many types of people, each with a different stake in what is being brokered and/or paid for. Designers provide the platform that allows transactions between groups and/or individuals. Campaign organizers use these sites to collect money/promote their ambitions. Sponsors and investors choose to put their money in, for a reward, a dividend or other return, such as feeling good. The platforms mediate interactions between these primary users (fundraisers and sponsors) and third parties, including platform owners, who may levy a fee for each transaction, online payment companies, which take a small cut of transactions (a $2-5 \%$ fee) and crowdfunding support companies (e.g. Kicktraq.com). Last, there are also beneficiaries, who have no direct engagement with the platform, such as the people that community or arts-based campaigns go on to involve and influence. These groups of people can all be understood as collaborating in the production of the socio-technical system of crowdfunding.

This means that platforms innovators sit at the center of a complex system of interrelations when they consider what the purpose, value and values of a crowdfunding system should be. We have chosen examples of crowdfunding with a social innovation angle, i.e. they are explicit about changing the world in some way. This enables us to see most clearly the kinds of change crowdfunding platforms could usher in and discuss how new publics might be created as part of this. To date, most research has focused on campaigns [e.g. 38] and organizer/sponsor relations [e.g
19], whereas we look at the underlying platform and the constellations that can be generated through design choices.

\section{Crowd}

Crowd in online activity dates to Wired magazine in 2006 and refers to a 'network of people' responding to an open call, either in 'the form of peer-production (when the job is performed collaboratively)' or, 'often undertaken by sole individuals' [22 n.p.]. These individuals form as a crowd through engaging with the platform, rather than having the collective and co-located status that has historically been intrinsic to crowds (though see Gupta for how 'turkers' find mutual support in crowdsourcing [20] and Hui on strategic support for self-help amongst crowdfunders [23]).

Historically, crowds are a problem. Sociologist Borch [4] says 'Due to the central role that the problem of crowds occupied in the early sociological thinking, it is virtually impossible to map out every account and discussion' (p8). Till recently, crowds drew theoretical attention for being unruly and challenging to social order. Park epitomizes this in distinguishing between crowds as emotional on the one hand, and publics as reasonable on the other [45].

In crowdfunding, multiple individuals co-fund ventures, just as, in crowdsourcing, many individuals co-source answers, solve problems and offer the wisdom of the crowd $[22,39]$. They may know each other or not, act in concert or not, but that is not their dominant characteristic - they are the help. In fact, we can be quite precise about who the individual members of a crowd contributing through a particular platform to a specific campaign might be, from friends and family to international networks of funders. But the term un-differentiates them and lumps them together.

\section{Publics}

We now turn to Dewey's work on how publics form round issues [14], drawing a parallel in how people gather with a common focus in the crowdfunding ecosystems we have been studying. In gathering, they form interest groups, more or less explicitly, contributing towards something being funded. We are not the first to use the idea of publics in HCI and design (e.g.[15,29,33,52]). In talking about publics, we refer here to the way that groups round platforms may be constituted by the actions of the platform. Where people related through platforms are not aware of each other at outset, the platforms (and campaign organisers) may work to build this awareness. Clearly, it is unnecessary to generate this level of collective sensibility for all crowdfunding, but we are looking at instances when such constellations can be usefully mobilized. We will look more closely at characteristics of building this awareness.

We note Le Dantec and DiSalvo's comments [29] on 'the contention, unevenness, and permeability of a public', saying that a public 'is usefully understood as a plurality of voices, opinions, and positions' and 'no single public, but rather a multitude of publics' [p243]. They embrace Dewey's public, 'not as a single generic a priori mass of 
people, but as a particular configuration of individuals bound by common cause in confronting a shared issue' [29: 243]. Further, Marres [35] argues that publics arise through (and can be seen in) how objects are constituted. So we might see crowdfunding platforms as materializing types of publics and being materialized by them.

Karasti [26] notes that 'Dewey's "publics" is a state-level concept', whereas she uses it for community-level activity in participatory design [p147]. Similarly, we can regard collecting, loaning and giving money for a particular social end as the construction of community-level publics round an issue. 'The public' is identified and constituted by an issue outside its immediate control [14]. In crowdfunding, possible engagement is determined by design factors in the hands of the platform-makers and in regulatory frameworks such as UK financial legislation, so participants have little control over the form of their engagement. Yet, these local publics can exert influence and play a part in enacting or resisting the goals of those setting the agenda. Murray et al [42] note the impact of/on an early group of funders: 'In February 2008, 26,000 people, responding to a web call, each put $£ 35$ into a newly formed co-op and bought a football club, Ebbsfleet United. Two months later many of the members - pioneers of a new form of financial collaboration - travelled to Wembley and saw their side win the FA trophy' [p112]. Similarly, the first community pub bought under the 2011 Localism Act in the UK was part-funded by 371 community shares, many in the hands of local people who drink there now with greater pride [31].

\section{METHODS OF DATA COLLECTION}

We interviewed the people behind several crowdfunding platforms with an interest in social innovation, to learn of their motivations and their ensuing design choices. By learning about their intentions and looking at how these are embodied in the platform, we can begin to discuss relations between design and configuring socio-economic activity. All our samples are from the UK. This does not affect the generalizability of our headline findings, since the overall relations we describe hold for other circumstances, but it may affect the detail, such as the regulatory framework and what counts as social innovation in a region.

We chose the sample presented here from a wider pool of interviews, some of which span several years, selecting those where the interviewees exhibited a clear intention to change social practice as well as raise money through crowdfunding. Light has, since 2004 (e.g. [30]), been following the progress of several activists using digital technology to solve social problems, some of whom run platforms. Another part of the motivation for the interviews was to gather qualitative data for UK research council funded projects on the sharing economy and crowdfunding led by the two authors. As mentioned, we have limited the sample to the UK, where we can talk within a common regulatory framework and one that allows a wide diversity of crowdfunding to flourish. We selected the cases, for variety and relevance, from our samples ( $\sim 15$ long-term studies by Light and $\sim 15$ more cross-sectional interviews by Briggs), choosing to feature four examples with related themes to make the points in this paper. Given there is no stable sample in such an entrepreneurial environment, we accept the inevitability of non-systematic sampling - this is not a complete overview, but examples chosen to show the new relations we observed. We have picked cases of innovators with social change ambitions that pair well to draw contrasts and find common ground: two attempting to change societal environmental behavior through providing a new financial mechanism and two that speak to a more general socio-economic trend in reconfiguring local relations (see table 1 ). We are not claiming all platforms show these characteristics, merely that attempting to shape social behavior is a discernible phenomenon. Within interviews, we paid rigorous attention to claims interviewees made for their platforms and design choices; how they spoke about goals and what support was given to enacting these goals as they pertained to social organization. We recorded all interviews, transcribed and analyzed them (see [48] on discourse analysis for process).

Our first interviews specific to digital platforms were conducted in 2009. Those we use come from between 2012 and 2016. Access to interviewees came through personal relationships and intermediary introductions over many years of participating in business, social and activist networks, and government forums. The benefit of coming in at the start with several initiatives, before launch, is that we have been able to trace progress and draw on it. In other words, long exposure to the sector informs our conclusions. We note the details in each sub-section.

\section{FOUR EXAMPLES OF DIGITAL CROWDFUNDING}

The descriptions here are drawn from the extended semistructured interviews with those in charge of (or acting as spokesperson for) a platform, interwoven with observations from watching their progress. In all cases, we asked our interviewees about why and how the platform got started, about opportunities and challenges in developing, launching and running it and about their plans for the future. Each interview covered aspects of motivation, beliefs, ethical orientation and ambitions for the platform, but we only draw on a narrow cross-section here to discuss social change elements and how these fit with choices and outcomes. As noted, we do not include material from users, either as fundraisers or funders, limiting this discussion to the ambitions of those behind the platforms for purposes of brevity and focus. Our goal is to map intention to design and offer initial thoughts on aspirations for crowdfunding. We have presented the studies in two pairs to reflect similarities between goals (see table 1): first, two platforms that engage with worldwide environmental sustainability in their choice of services, and then another two that seek to make more generic socio-economic change toward regional social and economic sustainability. 


\begin{tabular}{|c|c|c|c|c|}
\hline Platform & Trillion Fund & Patchwork Present & $\begin{array}{l}\text { Newcastle CC } \\
\text { (Funding Circle) }\end{array}$ & Crowdfunder \\
\hline & \multicolumn{2}{|c|}{ Driving new societal environmental behavior } & \multicolumn{2}{|c|}{ Changing local socio-economic configurations } \\
\hline Description & $\begin{array}{l}\text { Ltd. company - } \\
\text { renewable energy } \\
\text { investments }\end{array}$ & $\begin{array}{l}\text { Ltd. company - } \\
\text { coordinated gift- } \\
\text { giving }\end{array}$ & $\begin{array}{l}\text { Local authority } \\
\text { working with Ltd. } \\
\text { company }\end{array}$ & $\begin{array}{l}\text { Ltd. company - } \\
\text { mobilizing } \\
\text { grassroots }\end{array}$ \\
\hline $\begin{array}{l}\text { Motivation } \\
\text { beyond profit }\end{array}$ & $\begin{array}{l}\text { Environmental } \\
\text { sustainability by } \\
\text { moving investment } \\
\text { into green fuels }\end{array}$ & $\begin{array}{l}\text { Minimizing waste } \\
\text { through coordinated } \\
\text { gift-buying }\end{array}$ & $\begin{array}{l}\text { Fast finance for local } \\
\text { firms by networking } \\
\text { local investors }\end{array}$ & $\begin{array}{l}\text { Support for groups, } \\
\text { start-ups and causes } \\
\text { to raise project funds }\end{array}$ \\
\hline Products & $\begin{array}{l}\text { P2P lending } \\
\text { Community shares } \\
\text { Bonds, Equity, etc }\end{array}$ & $\begin{array}{l}\text { Customized donation- } \\
\text { reward system for } \\
\text { aggregating presents }\end{array}$ & P2P lending & $\begin{array}{l}\text { Reward } \\
\text { Donation } \\
\text { Community shares }\end{array}$ \\
\hline
\end{tabular}

Table 1: Summary of characteristics of our four case studies

\section{CASE STUDY: THE TRILLION FUND}

Trillion Fund claimed to be 'the UK's largest social crowdfunding platform' in April 2015 (video [53]), with a turnover in millions and 7000 members. The material here is taken partly from interviews with Julia Groves, the former CEO in 2012 before the service was launched, further conversations through the life of the platform (not cited directly), and from the platform website, as noted.

The platform is principally a P2P loan, rather than an equity model, enabling the spreading of investments and a range of 'raises' to support. However, there are some opportunities that involve issuing community shares: 'By joining, you are becoming part of a community that has a broader objective than just maximizing returns for investors' [52]. The team that set up Trillion Fund ('crowdfunding for people, planet and profit' [52] was motivated by the need for large loans and advances to small energy companies wanting to innovate with renewables. They were already successful entrepreneurs and the target (in the name) was to help generate the '\$1 trillion of annual global investment required to reach the scale of clean energy generation needed to prevent further global warming' [52]. Motivation was commercial and environmental, a business to make money for the platform owners while diverting existing funding to greater global ecological wellbeing. This mix of missions ran through all aspects, informed by the belief that investors tend to look at returns first: 'I don't care immediately why people are investing in renewables. I want them to invest in renewables and then make money. Profit is the motivation that breaks down barriers and makes people aware. We have to preach to the unconverted because that is the majority.' (Groves, interview). The owners felt it important that the model did not rely on the ethical commitments of its investors; instead, investors agree a rate of return on their loan, made directly to any company trying to raise funds, but brokered by the site. The platform acts as a two-sided market, allowing investors to search for and manage opportunities that range from supporting major energy infrastructure projects to social enterprises, and providing companies seeking funds with investment. The team promotes their featured energy companies, both on the site and beyond, and campaign for more funding and subsidy for the renewables sector. This is to be witnessed in the blog accompanying the platform, and has included a high-profile celebrity party to encourage awareness and investment. This promotion can be seen as part of making the site commercially successful, but also as a pragmatic strategy to promote renewable investment.

In a shock move, the platform closed to all future business in September 2015. The service was like many P2P lending platforms, but, in specializing in the renewable sector that was made viable by government subsidy, it became vulnerable to changes in national funding policy. 'Most renewable energy projects in the $U K$ are dependent on subsidies to provide returns to lenders. The level of subsidy is dropping rapidly and it is not clear what projects will be seeking funding going forward. As a business, Trillion incurs significant costs in marketing new loans and the Board has decided it is not prudent to continue to offer loans without visibility of future funding and project opportunities' [53]. Existing clients, based on more than 120 capital 'raises' in the area of renewable energy, continue to borrow/lend through the site but there are no new campaigns. Instead, the company is developing its technology and crowdfunding administration services and Groves has left to pursue energy initiatives elsewhere.

\section{CASE STUDY: PATCHWORK PRESENT}

The second study in this pair involves a gift-aggregation platform. An interview with platform designer and business owner Olivia Knight was conducted shortly after it went live in 2014. Knight left a job at an environmental charity to set up the platform, which she runs from a shop in South London, stressing both local presence and green ambitions: 'The principles are about being resourceful, using our money wisely to invest in things that are wanted and needed 
and not buying each other a ton of crap that we don't need, that ends up in landfill'.

Patchwork Present [46], with the styling of a rewards-based service but the function of a donation system, supports groups of people buying a single collective present. An item, like a bicycle, or series of elements, like those for a honeymoon, are divided into manageably-priced bundles, shown in a patchwork image on the website, under the slogan: 'Get friends and family together to fund one gift that's really wanted - piece by piece'. Then each donor pays for a part, directly into the recipient's Paypal account, and the site levies a fraction of the cost. Knight raised the money to fund the project through patchwork principles, involving 25 individual investors who all have $1 \%$ of the business. The company raised $£ 250,000$ in 20 days.

She says that the idea came to her as she planned her own honeymoon, worrying about the taboo of asking for money: 'gift giving should have some element of ritual to it and it shouldn't just be a financial transaction.' She created a website with imagery suggesting the things she wanted to buy and a rough price, directing friends and family to this instead of a wedding list. 'So they could choose a physical thing like two beers in a bar or a night in a hotel.'

The platform allows for customization, in choosing images, prices, etc. and in then allowing you to send a personal "thank you" to the individuals who bought each piece. 'So you can send pictures of you drinking your beer on the beach to all the people who bought the beer.' The effort people put in has impressed Knight. There are ready-made patchworks for use, but people go further, for instance the couple getting married, who not only made a patchwork themselves, but staged what they wanted to do, took pictures of themselves doing it and uploaded the images.

The site takes $3 \%$ of each contribution. This contrasts with other platforms, such as Kickstarter [27] and Just Giving [25], which charge more, or Taskrabbit [51] with a $20 \%$ service levy. 'In terms of competition, our commission is quite low. That will be one of the things we will have to look at - the sharing economy only really works when you reach scale. So there won't really be any money to be made until we reach real scale.' This figure was chosen from a user's point of view 'and just intuitively what feels right. What's quite nice is, on the average wedding gift, it works out at the same price as a piece of wrapping paper.' Knight points out an advertising-supported model would not work, nor would affiliation to retailers, but even in 2017, it remains early days in terms of financial viability.

\section{CASE STUDY: NEWCASTLE CITY COUNCIL}

This loan platform and portfolio shows the working, for mutual benefit, of branded 'white label' platform products (i.e. developed to be branded by others) in a partnership between a council and a technology provider. The account is based on interviews in 2014 with Cllr Michael Johnson, an elected member who instigated the initiative at this northern English council, and with Sophie Chappelow, senior marketing and partnership manager at P2P platform Funding Circle [17]. The interviews were conducted a few weeks after the launch of the new council-backed lending scheme. Briggs also then ran a series of crowdfunding workshops and roundtable events in northeast England.

Newcastle City Council is supporting the supply side of business finance, because 'traditional methods of raising capital were no longer working for companies' (Johnson, interview). The council believes lending decisions should be based on flexible criteria, with a quicker turnaround than that of traditional banks, which can take months to respond to a loan request (by which time opportunities have often passed). The elected member, who works as a professional business consultant, was aware of people locally 'who didn't have experience of investing in businesses and who didn't have sufficient capital to become Angel investors, but who had enough money to be managing their personal investments'. Johnson judges that, being risk averse, these individuals are unlikely to invest in businesses directly, but are 'probably socially motivated'. These characteristics, and Johnson's own interest in P2P lending prompted him to find a way to "provide them with an investment product that not only presents itself as a lower risk option [but] also has a social benefit of restricted investment criteria - so it has to give back locally, perhaps introduce a premium to firms that invest in apprenticeships or that pay a living wage.'

A policy was introduced enabling the city council to codesign a product with Funding Circle. Previously, '[the council] would have taken on a fund to do that and ... it might be the cost of hiring three or four people to manage this pot of money' (Chappelow, interview). The partnership is intended to enable council and lenders to benefit through the low cost of each financial transaction and, overall, a fast, easy and inexpensive business loan supply service.

Funders make loans from 6 months to 5 years. They select companies to invest in based on the credit model given a proposal (banded $\mathrm{A}+$ to $\mathrm{C}$ - depending on risk) and offer loans in return for annual interest of between $6 \%$ and $15 \%$. Investors can assess the viability of a loan request by conducting online searches and the platform facilitates queries via direct communication with those seeking funds. Alternatively, the platform 'auto-bid' function auto-matches an investor to suitable investments, based on their appetite for risk and desired interest-rate reward. Like Trillion Fund, all money is held by clients rather than with the platform and investors make their own decisions. This puts financial risk with investors (including the council which is a lender), rather than with the platform makers.

Funding Circle promotes itself as a technology company (not as crowdfunding or finance), designing and managing all the algorithms that support bidding (Chappelow). It views its partnership with a local authority as building 'an element of trust. We know we're trustworthy, but conveying that? People will go: "Oh, well I probably wouldn't have 
trusted them before but if the council is involved...". Trust is a big element of it.' (Chappelow). In this way, the partnership operates as advocacy not only for the platform but also for the P2P sector.

There are, however, tensions specific to the ambitions of the council in using networked finance. The council wants to keep invested money local, whereas the platform autobid algorithms factor in 'diversification' (of sector and geography) to mitigate, or, at least, spread, investment risk for funders. And, anecdotally, take-up of council loans on Funding Circle has been slow; several months into the scheme only one had been authorized and problems persist, with low take-up across northeast England [56]. Marketing at launch was hampered by timing, running into constraints on public communication in the lead up to elections. Other issues concern eligibility, with applicant companies not having a requisite Newcastle postcode; and companies finding the credit requirements of the platform as onerous as conventional bank loans, requiring two years' accounts.

\section{CASE STUDY: CROWDFUNDER}

The UK's nearest equivalent to Kickstarter is Crowdfunder, Britain's major rewards-based platform, which supports community enterprise, charitable donation and product generation. Material comes from conversation and collaboration with the platform [10] in 2014-5, and a 2016 interview with Crowdfunder's fund manager Jason Nuttall.

Crowdfunder focuses on social issues, partly organized by geographical location. This is counter-intuitive given the scaling potential of automated platforms, but works to grow audience for local activity. 'Crowdfunder Local' on the platform website features area-specific campaigns to show off campaigns, e.g. 'Crowdfund Somerset showcases the best crowdfunding projects in the county. If you have a community group, business, charity or other great idea then add your project today.' [10d]. The platform is very active in scouting for and helping to encourage both new projects and new partnerships. 'The team has taken an entrepreneurial approach to developing new partnerships' (website). For instance, Crowdfunder works with several UK universities running micro-crowdfunding sites [10b]. It fosters small, located enterprises such as Leeds Bread Cooperative (LBC), which used the platform to raise money to buy ovens to set up a business. Their campaign raised $£ 8,690$ in 42 days from 114 backers. In the process, the bakery built an online local public that converted to a customer base beyond the campaign [10c]. LBC then received grant funding from a cooperative legacy fund and other business loans in what Chappelow (at Funding Circle) refers to as the 'multiplier effect... making that money work a lot harder' (interview) and aggregating sources of finance beyond that sourced via the platform. Funding manager Nuttall visits traditional funders to explain how matchfunding funds communities are managing to collect can improve impact for their budgets and these projects' reach.
Nuttall is personally interested in developing the platform to gather and redistribute resources beyond money, such as gifts-in-kind and time. These forms of exchange are useful to social enterprises, building up support around them. He points to the novel structures that have been enabled by the platform's support, such as a community-owned distillery (which asked for $£ 1.5 \mathrm{M}$, received $£ 2.5 \mathrm{M}$ and is building a visitor center with the extra money: growing tourism and further including its funders). Nuttall points to the value gained in organizing a social initiative with a campaign: it builds long-term engagement, extending first commitments with news, encouragement and more opportunity. The campaign structure provides the frame for a relationship between those running a campaign and those sponsoring it. 'It can show what that project goes on to do. And, if there's a delay, people are more forgiving as they understand the dynamics and are being kept up to date. It makes for better publicity for any hazards.' (Nuttall, interview). He suggests that people are not merely sponsoring, shopping or even building a brand; they are in the process of becoming the network through which the aims of enterprises are realized.

Crowdfunder's $\mathrm{P} 2 \mathrm{P}$ relations mean that projects need to deliver, producing tangible assets that can be witnessed by these networks. Much support goes into helping organizers choose a suitable project, plan and schedule: 'to do $X$ by $Y$ with Z' (Nuttall). Would-be founders struggle with this and lack the confidence to tackle the necessary practical skills, especially making a video. Crowdfunder provides coaching to people starting out on the platform.

The platform's lineage already tells a story of constellation, emerging at scale through mergers and acquisitions of small, novel and innovative (if less sustainable) platforms, and partnerships with government departments and an equity platform. A platform was launched in 2011 as Peoplefund.it, which, in 2012, merged with WeDidThis - a platform specializing in arts funding through collective sponsorship. The platform then merged with Crowdfunder, a small rewards-based site that had been set up by the equity platform Crowdcube. Together, the merger launched as Crowdfunder.co.uk with a greatly expanded network [10b]. Plymouth University came on board as co-owner to promote education in enterprise. In 2014, Crowdfunder ran a campaign on its partner platform Crowdcube raising $£ 650 \mathrm{k}$ in one morning, and, in late 2015, ran another campaign raising more than $£ 1.3 \mathrm{M}$, for nearly $9 \%$ of Crowdfunder's equity [9]. This period also marked the beginning of government and charity-backed matchfunding community crowdfunding schemes to promote local impact of social change projects [10d]. In June 2015, Crowdfunder began offering community share partnerships. At time of writing, more than $£ 32.5 \mathrm{M}$ ( US\$40M) had been raised for projects across the UK [10].

\section{DISCUSSION}

We have presented some key platform types - equity, donation, rewards, loan - and begun to link structure to 
socio-economic goals. There are features common to all our examples, such as using algorithms to manage transactions and networks to connect up markets. And there are marked differences, such as how campaigns are built and how they anticipate long-term viability. But we do not want to limit our discussion to such features here. Instead, we want to address questions about how relations are managed and, thus, how paying publics are brought into being.

\section{Ambitions for Social Outcomes}

Our interviews with platforms makers show that socioeconomic intentions informed the design of each, with a goal of assembling people to a specified societal end.

'Trillion Fund is changing money' says the platform's site. Accompanying the owners' aims to capitalize for profit on new forms of financial mechanism are social, political and environmental ambitions. Their aim was to mobilize the huge sums needed to secure enough renewable energy to impact climate change. Within their strategy, they knew a competitive rate of return on investment was nonnegotiable: it would be impossible to woo investors on the strength of a green portfolio alone. Nonetheless, their marketing and careful vetting of portfolio speak to their concern to use the platform to enable green initiatives to compete with existing forms of energy generation and replace them. Talking to the CEO and other team members reveals a passion to change not financial relations, but directions of funding and a pragmatic goal of using a financial tool to do so. They hoped that people would come for the profits and stay for the politics, intending to form a public who is increasingly interested in renewable energy because they have invested in it. Ironically, their most effective move to generate collective interest may have been to suspend new schemes (after change in subsidy policy), arousing group concern from platform investors about the safety of their investments. But here too they attempted to turn investor and media attention into fuel for a campaign on subsidies and change from traditional energy sources, using the interest to make their point and unite their investors. The headline on site remains 'Why pull money out of coal, oil and gas?' Existing investment shows that ethical products with good returns can appeal, belying Agrawal et al's [1] finding that giving for the common good and for a good return are mutually incompatible. What may be true at individual level looks different when viewed as a commercial strategy intended to make social and political change. However, without government renewables subsidy the platform itself becomes less viable.

Patchwork Present also aims to have positive environmental impact, changing social practice and enabling personalized services that are more than a sum of its parts. Here, the mechanism for bringing this about is offering a new, easy way for gift-giving, using the power of the network to communicate, connect, broker and to manage and aggregate money. Knight can point to the elaborate creative work done by users as an endorsement of the effort she put into devising a clear and configurable set of interactive visual elements. The effect of success would be to cut down on poor resource use (unwanted gifts), whether or not her customers use the service because of green principles.

But it is when we turn to Crowdfunder and the 'white-label' council platform that we see intended societal remodeling most nakedly. Agnostic about what kind of campaign they support, as long as they are legitimate, both the reward- and loan-based platform stress their potential to move money into enterprises that (increasingly) struggle to find flexible support elsewhere, creating a new wave of entrepreneurship funded collectively by individuals. Both want to work at a local level and Crowdfunder is able to link fundraising with community generation, witnessed here in the new market for artisan bread in Leeds born of the campaign to launch it.

The other platforms are not as successful as the last. They may be assembling people around them, but not always at a scale that offsets the cost of doing so. We are not discussing tactics for running a viable service, but looking at the world-changing ambitions of the platforms and how these aspects are enacted. Although still seen as a novelty by many users, the platforms regard their mission as changing the whole way society distributes and/or makes money (and/or what it lends on). We note that everything from government policy to onerous authentication requirements to lack of advertising opportunity can hamper development. These aspects have discernible impact on viability, i.e. parts of the constellation create challenges, but it does not negate the potential to meet these challenges and make big change. All four sites have engaged people in crowdfunding in ways that the owners have chosen, so as to make societal change.

\section{Publics: Mutual Awareness and Trust Issues}

Publics form round issues [14] and objects representing issues [35], and mutual awareness grows through issue formation. Only one of our studies presupposes existing relations. Patchwork Present provides the means to join people in a collaborative act where mutual awareness is already high. It brings together people who wish to do something for someone else and many will be known to each other as the recipient's friends. Often friends do support campaigns and the outcome is an aggregation of resources that collectively supports individuals. Patchwork Present, in making a present, does not need to bring people into contact, but it does involve them in an activity that would not happen without a sense of collective connection and loyalty to the gift's recipient. Most platforms do not assume loyalty from anyone, even if individual campaigns may depend on family and friends.

Nonetheless, other people's behavior is an influential factor across platforms in attracting funders and giving them confidence to invest. People need to see others taking a risk and making it work. Conversations in 'how to' workshops co-run by Briggs for would-be campaign fundraisers suggest crowdfunding is about authenticity, trust and where money has come from, also, crucially, being able to signal 
and assess these online. Making enough money to sustain platforms' business may be paramount, but a prerequisite is making crowdfunding socially acceptable.

As noted, the Crowdfunder Local pages make destination campaigns for many cities and regions to promote clusters of people and activities. Local clustering can create what Light and Miskelly call 'a relational asset' in an area [32: 55 ] where 'no one is working in isolation. Borrowing goes on between projects and the effort to find materials, support and funds is often shared'. This kind of environment makes a fertile bed for crowdfunding, drawing in new adherents as the idea becomes more integrated and a more usual way to raise funds or offer support. We can see a zone of influence constructed beyond immediate actions on the platform.

Thus, Murray and colleagues [42] propose that the act of giving in crowdfunding is not the transfer of funds for a good cause, but a gateway to greater engagement. ...It provides a micro thread for continuing civic involvement.' [42:114]. Relatedly, partnerships are about supplying traffic and signaling trust, shown in the gratitude Funding Circle has for its council partner in Newcastle. The partnership is significant for how the platform is accepted, beyond any individual campaign. It is interesting that a council is acting as the face of the new mechanism, showing an ability to reinvent itself, but also the complexity of the journey for new financial instruments if they are to be taken up by all echelons in society and all areas of the country/world.

\section{Rewards and Returns}

If ambitions and team involvement shape the service round a platform (and so the nascent social outcomes), so does the reward. The time-sensitive group pledge model (All or Nothing), when a minimum must be reached by a fixed date, is more likely to activate a community round a campaign than a slow climb to funding would [54].

The effect noted here is broader-brush. For instance, Patchwork Present uses a donation-reward hybrid model with particular challenges. The design is more elaborate than most donation platforms because it has to deal with the fact that, at root, the user may be asking for money for their personal gain, unlike charities or sponsored activities. In this, it is closer to art and social enterprise platforms, which have to convince potential funders that something exciting is to be done with their money. Thus, the platform offers creative tools and resists the disembodiment of a virtual present by making it 'real'. Money, the shared commodity, is rendered material through design that uses images to present a patchwork of items; offers a 'thank you' mechanism that reinforces the idea of actual goods; and equates the cost of the service to the wrapping paper round a present. The payback may be the fun of using the site and the talking point created in the present-giving network.

There is also clearly a difference between supporting a bakery, from which you can buy bread afterwards, or a distillery, when your shares come with a favorite drink, and lending only for promised income. Loan models are not intrinsically social and the rewards they promise are profit. They are more likely to have users who remain remote from each other, making it harder to create publics. (That is, until a platform is threatened or legislation changes dramatically, when, like Trillion Fund, there is collective interest in future activities and the safety of lender money.) Yet Trillion Fund celebrity shareholder Vivienne Westwood held a party to attract investors and raise awareness of renewables, a specifically social occasion for a service that does not need to bring its users into contact. While this is good business and promotion, there is also a rationale for the particular choice of engagement that draws on their social mission to accumulate a constellation around them.

Other intermediaries are rewarded by even a small amount of paying business. This is clearest in Patchwork Present using Paypal as a platform for its own service; payments collected contain a levy for this third party. And all income contributes to paying shareholder dividends. In fact, the constellations that Patchwork Present is configuring are far from straightforward and, as a consequence, there is no single public. They include a patchwork of investors, its campaign focus on a recipient known to all the funders, and the visible use of third-party technology products (unlike the 'white-labeling' described in the council study), This hybridity is visible to some degree across all our examples, with no simple meeting of markets, publics, or both.

\section{DESIGNING PAYING PUBLICS}

We have argued that platforms can be used to configure the constellations of people that are involved in crowdfunding by bringing them into being in particular relations round socio-economic issues (and objects that represent issues, such as the platforms themselves). We have likened this to publics as they are discussed by Dewey [14] and in HCI and design $[15,29,33,52]$. The particular character of these interactions is financial, because of the financial nature of direct engagement with the platform. All the focus is on the movement and redistribution of funds and what they will buy. This is why we have talked about 'paying publics' in our title, drawing attention to the way that crowdfunding platforms create interests of an economic kind. Yet, we are not just talking about new markets.

Markets are full of crowds, masses of people who happen to be together. We make the distinction between markets, which are purely economic, and publics, which are social and political; between crowds, which are happenstance, and publics, which evolve and shape (as well as being shaped). We can make this distinction since each platform described here has a goal beyond making money through bringing together types of market; it has sought to provide social and ethical interests of the kind that configure publics. There is awareness of contributing to, and benefitting from, building new types of financial mechanism that may change societal relations, albeit within a global context where neoliberalism has depoliticized finance. But there is also awareness of the 
potential for impact in/on a particular sector through new relations, be that renewable energy or local business. No platform is redesigning economic life, despite Trillion Fund's claim it is 'changing money'. However, each offers possibilities for linking private, public and personal money and services in new ways round issues of concern, and, together, that signals societal as well as financial change.

In our first pair, the publics constituted are global, united by use of a platform to drive new collective environmental behavior and, as such, less obviously social in an immediate sense. In the second, concerns are defined as local (part of a localism agenda) and publics are thus geographical, where new relations among communities are an expected outcome as well as higher-level societal structures. We have given two examples of each to show that platforms can work in quite different ways to effect social change - and the related paying publics look different too.

\section{Design of Paying Publics}

We have shown four ways that crowdfunding platforms can operate with articulated areas of concern. For each, the owner/designer talks of a desire for transformation: forms of financial human-computer interaction that enable new opportunities for local and global groups with evolving common interest. We have called constellations round these sites 'paying publics' to express the new financial and socio-economic structures of the arrangement.

Platforms can be easy to build - an off-the-shelf payment system, content management system and a fairly standard interface design. This makes the generosity and size of a platform's publics key to its effectiveness and this hinges on its unique design. Crowdfunder, the UK rewards-based platform, in many ways closely resembles the standardized design of world leader Kickstarter (video, text campaign message below, ladder of increasingly expensive rewards in a right-hand column). Yet, Crowdfunder's business model and design of services (such as coaching to potential founders) is significantly different. Crowdfunder is actively shaping publics through partnerships and local engagement. Nuttall is teaching would-be founders what a campaign is, securing match funding for these enterprises, helping them build take-up of services as well as campaigns and so changing how such organizations operate.

The design round the platform, of relations built with each neighborhood and wider social structures, becomes key to gathering and shaping a paying public. This may also be key to the platform's viability: the ability to attract users. But we hope to have shown that something more than mere use can take place in engaging in the new forms of financial practice now available with crowdfunding.

A crowd uses a platform. A paying public emerges as it develops a collective sense as an interest group able to fund particular outcomes through placing its money. As these publics evolve, platforms become more than infrastructural, they are a support, a magnet and a focus for societal trends and what it is possible to enact with a popular groundswell. We are watching a vanguard, using algorithms to enable and automate interactions. Yet we may be reminded of the subscription models used in the $18^{\text {th }}-19^{\text {th }}$ century in Britain and other parts, when people provided and shared activities and resources without state or local government mediation.

We can point to the work of active public-building that our studied platforms engage in: promoting mutual awareness by showing user activities on site, in newsletters and blogs; flagging up campaigns (particularly successes) and listing numbers of pledges as well as pledged amounts; running events round campaigns; teaching founders how to organize campaigns and tell a compelling story about their goals; showing how to turn a public into customers and realigning organizations to benefit from match-funding initiatives and crowdfunded outcomes; thinking geographically as well as thematically about who the public might be. We can also note that legal and regulatory matters shape what platforms can do; and changes in financial and political climate have an impact on how publics form and what concerns them. The sector will continue to change fast. For instance, the new act in the US means a range of start-ups and businesses that were constrained to using rewards-based platforms can now access professional investment.

Last, we can ask, speculatively, what impact the growth of these new formations could have. Locality has not been written out, despite the global reach of networks, but new forms of public commissioning raise questions of justice, equity and inclusion. We cannot predict if these variants on subscription will provide service for all, or just subscribers. Loans continue to define a borrower and a lender, even if the lending is distributed, but there is social import to this change. Murray et al's [42] football fans buying their club, then going to support it, or the drinkers in the communityowned pub are potentially the start of a more profound trend that the platforms here are seeking to contribute to.

Should we predict the reinvention of publics as paying publics round hundreds of new transaction mechanisms and their shapes? Design considerations for these interventions go beyond interface and interaction design, on one hand, and shaping viable business, on the other, to consider how we want our societies organized and funded and how we acknowledge social justice issues [16] in making financial choices. Crowdfunding platforms collectively change the economic landscape and could enfranchise new pockets of society to contribute and see their choices enacted - in ways defined by the subtleties of each platform's design - but only if they are designed to do so.

\section{ACKNOWLEDGEMENTS}

We are grateful for support from multiple grants: EPSRC [EP/K003593/1] and ESRC [ES/M00371X/1]. We thank our interviewees, collaborators and the $\mathrm{CHI}$ reviewers for their comments. Due to ethical concerns, some supporting data cannot be made available. See [31] for data in the public domain; or check with the authors (emails above). 


\section{REFERENCES}

1. Ajay Agrawal, Christian Catalini and Abi Goldfarb, 2010 (online version). The Geography of Crowdfunding. NBER Working Paper No. 16820 http://www.nber.org/papers/w16820.pdf

2. Paul Belleflamme and Thomas Lambert. 2014. Crowdfunding: Some Empirical Findings and Microeconomic Underpinnings. SSRN Electron. J. doi:10.2139/ssrn.2437786

3. Victoria Bellotti, Sara Cambridge, Karen Hoy, Patrick Shih, Lisa Handalian, Kyungsik Han and John Carroll. 2014. Towards Community-Centred Support for Peerto-Peer Service Exchange: Rethinking the Timebanking Metaphor. In Proceedings of the 2014 SIGCHI Conference on Human Factors in Computing Systems (CHI'14). New York: ACM Press, 2975-2984. http://dx.doi.org/10.1145/2556288.2557061

4. Christian Borch. 2012. The Politics of Crowds: An Alternative History of Sociology. Cambridge University Press.

5. Pierre Bourdieu. 2005. The Social Structures of the Economy. Polity Press.

6. Geoffrey C. Bowker and Susan Leigh Star. 2000. Sorting Things Out: Classification and Its Consequences. MIT Press.

7. Jo Briggs, Celia Lury and Sarah Teasley. 2015. Creative Temporal Costings: A ProtoPublics Research Project with Leeds Creative Timebank. http://nrl.northumbria.ac.uk/24800/

8. Ed Collom, Judith Lasker, and Corinne Kyriacou (eds.) 2012. Equal Time, Equal Value: Community Currencies and Time Banking in the US, Burlington VT: Ashgate.

9. Crowdcube (crowdfunding campaign, no date) www.crowdcube.com/investment/crowdfunder-19203

10. Crowdfunder (website) http://www.crowdfunder.co.uk b. http://www.crowdfunder.co.uk/blog/crowdfundingwent-mainstream-crowdfunder-story/ c. http://www.crowdfunder.co.uk/leeds-bread-coop d. http://www.crowdfunder.co.uk/campaigns/local

11. CrowdingIn: Crowdfunding in the UK (website) $\mathrm{http}: / /$ crowdingin.com/platforms/all/all\#

12. Roel Davidson and Nathaniel Poor. 2016. Factors for success in repeat crowdfunding: why sugar daddies are only good for Bar-Mitzvahs, Information, Communication \& Society, 19:1, 127-139 DOI=http://dx.doi.org/10.1080/1369118X.2015.10935 33

13. Rodrigo Davies. 2014. Three provocations for civic crowdfunding. In Information, Communication \& Society. 18 (3). http://dx.doi.org/10.1080/1369118X.2014.989878
14. John Dewey. 1927. The Public and its Problems. New York: Holt.

15. Carl DiSalvo, Jonathan Lukens, Thomas Lodato, Tom Jenkins, Tanyoung Kim. 2014. Making public things: How HCI design can express matters of concern. In Proceedings of the 2014 SIGCHI Conference on Human Factors in Computing Systems (CHI'14). ACM, New York, NY, USA, 2397-2406. http://dx.doi.org/_10.1145/2556288.2557359

16. Lynn Dombrowski, Ellie Harmon, and Sarah Fox. 2016. Social Justice-Oriented Interaction Design: Outlining Key Design Strategies and Commitments. In Proceedings of the 2016 ACM Conference on Designing Interactive Systems (DIS '16). ACM, New York, NY, USA, 656-671. http://dx.doi.org/10.1145/2901790.2901861

17. Funding Circle (website) https://www.fundingcircle.com/uk/

18. Annabelle Gawer. 2009. Platforms, Markets and Innovation: An Introduction. In Platforms, Markets and Innovation. Annabelle Gawer ed. 2009. Edward Elgar, 1-16.

19. Elizabeth Gerber and Julie Hui. 2013. Crowdfunding: Motivations and deterrents for participation. In $A C M$ Transactions on Computer-Human Interaction (TOCHI) 20 (6): article no. 34. http://doi.acm.org/10.1145/2530540

20. Neha Gupta, David Martin, Benjamin V. Hanrahan, Jacki O'Neill. 2014. Turk-life in India. In Proceedings of the 18th International Conference on Supporting Group Work (GROUP '14), 1-11. http://doi.acm.org/10.1145/2660398.2660403

21. David Hakken, Maurizio Teli, Barbara Andrews. 2016. Beyond Capital: Values, Commons, Computing, and the Search for a Viable Future, Routledge

22. Jeff Howe. June 2, 2006. Crowdsourcing: A Definition. Crowdsourcing Blog.

23. Julie S. Hui, Michael D. Greenberg, Elizabeth M. Gerber. 2014. Understanding the role of community in crowdfunding work. In Proceedings of the 17th ACM conference on Computer supported cooperative work \& social computing (CSCW '14), 62-74. http://dx.doi.org/10.1145/2531602.2531715

24. Jumpstart Your Business Startups Act Wikipedia https://en.wikipedia.org/wiki/Jumpstart_Our_Business _Startups_Act

25. JustGiving (website) www.justgiving.com

26. Helena Karasti. 2014. Infrastructuring in participatory design. In Proceeding of the Participatory Design Conference, (PDC 2014), p142-150. http://doi.acm.org/10.1145/2661435.2661450

27. Kickstarter (website) https://www.kickstarter.com/ 
28. Kicktraq (website) https://www.kicktraq.com

29. Christopher Le Dantec and Carl DiSalvo. 2013. Infrastructuring and the formation of publics in participatory design. In Social Studies of Science 43(2) 241-264. DOI: 10.1177/0306312712471581

30. Ann Light and Clodagh Miskelly, (2008) Brokering between Heads and Hearts: an analysis of designing for social change, Proc. Design Research Society 2008 (DRS '08).

31. Ann Light and Clodagh Miskelly. 2014. Design for Sharing, Sustainable Society Network+: https://designforsharingdotcom.files.wordpress.com/20 14/09/design-for-sharing-webversion.pdf

32. Ann Light and Clodagh Miskelly. 2015. Sharing Economy vs Sharing Cultures? Designing for social, economic and environmental good, IxD\&A, 49-62 http://www.mifav.uniroma2.it/inevent/events/idea2010/ doc/24_3.pdf

33. Silvia Lindtner, Judy Chen, Gillian R. Hayes and Paul Dourish. 2011. Towards a Framework of Publics: Reencountering Media Sharing and its User, ACM Transactions on Human-Computer Interaction (ToCHI), 18 (2) Article 5. http://doi.acm.org/ $10.1145 / 1970378.1970379$

34. John Lyons. 2007. Place-Shaping: A shared ambition for the future of local government, HMSO, London

35. Noortje Marres. 2007. The issues deserve more credit: Pragmatist contributions to the study of public involvement in controversy. In Social Studies of Science 37(5): 759-780. http://sss.sagepub.com/content/37/5/759.full.pdf + html

36. Doreen B. Massey. 1995 ( $2^{\text {nd }}$ edn). Spatial Divisions of Labor: Social Structures and the Geography of Production, Psychology Press.

37. Tanushree Mitra and Eric Gilbert. 2014. The Language that Gets People to Give: Phrases that Predict Success on Kickstarter. In Proceedings of Computer Supported Cooperative Work (CSCW'14), 49-61. http://dx.doi.org/10.1145/2531602.2531656

38. Ethan Mollick. 2014. The Dynamics of Crowdfunding: An exploratory study. In The Journal of Business Venturing, 29 (1), 1-16. http://dx.doi.org/10.1016/j.jbusvent.2013.06.005

39. Ethan Mollick and Ramana Nanda. 2016. Wisdom or Madness? Comparing Crowds with Expert Evaluation in Funding the Arts. In Management Science 62(6):1533-1553. DOI: 10.1287/mnsc.2015.2207

40. Jonathan Moules. 2014. London emerging as world leader in crowd-funding. Financial Times, 15 August 2014: http://on.ft.com/1uJ5ujJ

41. Michael Muller, Werner Geyer, Todd Soule, Steven Daniels and Li-Te Cheng. 2014. Crowdfunding inside the Enterprise: Employee-Initiatives for Innovation and Collaboration. In Proceedings of the SIGCHI Conference on Human Factors in Computing Systems (CHI '14), 503-512. http://doi.acm.org/10.1145/2470654.2470727.

42. Robin Murray, Julie Caulier-Grice and Geoff Mulgan. 2009. Ways to Design, Develop and Grow Social Innovation: Social Venturing. Nesta and the Young Foundation.

http://www.nesta.org.uk/sites/default/files/social_ventu ring.pdf

43. Laurent Muzellec, Sébastien Ronteau and Mary Lambkin. 2015. Two-sided Internet Platforms: A Business Model Lifecycle Perspective. In Industrial Marketing Management, 44 (2), 139-150. http://dx.doi.org/10.1016/j.indmarman.2015.02.012

44. Andreas Novy and Bernhard Leubolt. 2005. Participatory budgeting in Porto Alegre: Social innovation and the dialectical relationship of state and civil society. Urban Studies 42, 11: 2023-2036. http://doi.org/10.1080/00420980500279828

45. Robert E. Park. 1975. The Crowd and the Public and Other Essays. University of Chicago Press.

46. Patchwork Present (website) www.patchworkpresent.com

47. Yannis Pierrakis and Liam Collins. 2013. Banking on Each Other: Peer-to-peer lending to business: evidence from funding circle. Nesta.

48. Jonathan Potter and Margaret Wetherell. Discourse and social psychology: beyond attitudes and behaviour. London Newbury Park, California: Sage. 1987

49. Stuart Reeves, Scott Sherwood and Barry Brown. 2010. Designing for Crowds. In Proceedings of the 6th Nordic Conference on Human-Computer Interaction (NordiCHI '10), 393-402 http://doi.acm.org/10.1145/1868914.1868960

50. Alexandra Stiver, Leonor Barroca, Shailey Minocha, Mike Richards and Dave Roberts. 2015. Civic crowdfunding research: Challenges, opportunities, and future agenda New Media \& Society, 17 (2), 249-271. doi: $10.1177 / 1461444814558914$

51. Taskrabbit (website) www.taskrabbit.com

52. Teli, Maurizio, Silvia Bordin, María Menéndez Blanco, Giusi Orabona, and Antonella De Angeli. 2015. 'Public Design of Digital Commons in Urban Places: A Case Study'. Int. J. of Human-Computer Studies 81: 17-30.

53. Trillion Fund (website) https://www.trillionfund.com

54. Rick Wash and Jacob Solomon. 2014. Coordinating Donors on Crowdfunding Websites. In Proceedings of Computer Supported Cooperative Work (CSCW'14) http://dx.doi.org/10.1145/2531602.2531678 
55. Anbang $\mathrm{Xu}, \mathrm{Xiao}$ Yang, Huaming Rao, Wai-Tat $\mathrm{Fu}$, Shih-Wen Huang and Brian P. Bailey. 2014. Show Me the Money! An Analysis of Project Updates during Crowdfunding Campaigns. Proceedings of the SIGCHI Conference on Human Factors in Computing Systems (CHI '14), 591-600.

http://doi.acm.org/10.1145/2556288.255704
56. Bryan Zhang, Peter Baeck, Tania Ziegler, Jonathan Bone and Kieran Garvey 2016. Pushing Boundaries: The 2015 UK Alternative Finance Industry Report, Nesta and Cambridge University

https://www.nesta.org.uk/sites/default/files/pushing_bo undaries_0.pdf 